удК 336.77.067:005

Л. О. Чашин

Московский государственный технический университет имени Н. Э. Баумана, 2. Москва, Российская Федерация

С. В. Клементьева

Московский государственный технический университет имени Н. Э. Баумана, 2. Москва, Российская Федерация

\title{
АКТУАЛЬНОСТЬ ФОРМИРОВАНИЯ РЕЗЕРВОВ ПО СОМНИТЕЛЬНЫМ ДОЛГАМ
}

\begin{abstract}
АНнОТАЦИЯ. В статье рассматривается актуальность самостоятельного формирования резервов по сомнительным долгам в сложившейся экономической действительности. Подробно описывается сущность такого подхода и отличия от традиционных путей формирования оценочных резервов. Изучается причина возникновения потребности в формировании резервов по сомнительным долгам. В статье не поднимается вопрос экономических санкций, девальвации рубля, нефтяного кризиса и различные геополитические проблемы, однако все эти причины, несомненно, являются предпосылками к усилению антикризисных мер, более тщательного анализа финансовой отчетности предприятия и оценке финансовой состоятельности своих партнеров. Именно поэтому особое внимание в статье уделяется различным методикам формирования резервов по сомнительным долгам для более точного отражения величины дебиторской задолженности, доходов и расходов и финансового результата деятельности организации в бухгалтерской (финансовой) отчетности.

КЛЮЧЕВЫЕ сЛОВА. Сомнительные долги; дебиторская задолженность; формирование резервов; бухгалтерский учет; методология.

ИНФОРМАЦИЯ О СТАТЬЕ. Дата поступления 28 ноября 2016 г.; дата принятия к печати 1 марта 2017 г.; дата онлайн-размещения 31 марта 2017 г.
\end{abstract}

L. O. Chashin

N. E. Bauman Moscow State Technical University, Moscow, Russian Federation

S. V. Klementyeva

N. E. Bauman Moscow State Technical University, Moscow, Russian Federation.

\section{RELEVANCE OF FORMING ALLOWANCES FOR DOUBTFUL DEBTS}

ABSTRACT. The article considers the relevance of independent formation of doubtful debt allowances in the existing economic reality. It describes in detail the essence of such an approach and differences from traditional ways of forming allowances. It studies the cause of arising a need for forming doubtful debt allowances. The article does not bring up an issue of economic sanctions, devaluation of ruble, the oil crisis and various geopolitical problems, however, all these reasons are undoubtedly the prerequisites to strengthening crisis response measures, to more careful analysis of the company's financial reporting and assessment of financial autonomy of its partners. For this reason, the article pays a special attention to various techniques of forming of doubtful debt allowances for more exact reflection of the size of receivables, incomes and expenses and the financial result of the organization's performance in accounting (financial) records.

KEYWORDS. Doubtful debts; accounts receivable; creation of provisions; accounting; methodology.

ARTICLE INFO. Received November 28, 2016; accepted March 1, 2017; available online March 31, 2017.

(ㄷ Л. О. Чашин, С. В. Клементьева, 2017

\section{Baikal Research Journal}


Введение. Заголовки статей в интернете и многих финансово-деловых изданий с начала 2012 г. сообщают о значительном влиянии мирового кризиса, как на банковскую систему [1], так и на всю экономику Российской Федерации в целом. И вот уже 2016 г. подошел к концу, а кризис и не думает заканчиваться. «Падение экономики временно приостановилось, но дно еще не достигнуто» - отмечает издательство «Ведомости» [2].

Такие негативные факторы как падение цен на нефть, неэффективность экономической системы и санкции Запада обуславливают рост инфляции и, как следствие, спад потребительской активности [3]. В конечном счете все сводится к снижению финансовых показателей многих организаций, вплоть до полной ликвидации [4]. Невозможно не принять тот факт, что настоящее время характеризуется ростом неплатежеспособности покупателей [5]. Рост количества организаций-банкротов среди дебиторов существенно влияет на финансовое положение экономических субъектов и принятие управленческих решений в отношении стратегии дальнейшего развития компании. Что же делать компаниям, чтобы смягчить удар от негативных веяний рынка?

В условиях столь неблагоприятной конъюнктуры объективная величина дебиторской задолженности играет немаловажную роль в обеспечении ликвидности и финансовой устойчивости организации, ведь помимо ошибок, допущенных случайным образом, встречаются и умышленные, т. е. совершенные для того, чтобы создать видимость успешной деятельности и маскировки недобросовестных действий, что вводит в заблуждение как внешних, так и внутренних пользователей [6]. Лишь адекватная кредитная политика, строгий финансовый контроллинг [7] и самая серьезная мобилизация усилий для продолжения деятельности позволят игрокам удержаться на рынке.

Таким образом, повышение контроля над дебиторской задолженностью с целью снижения риска нанесения ущерба экономическому субъекту из-за задержек платежей и предотвращения манипулирования финансовым результатом является одной из актуальных проблем последних лет [8].

Однако, такой серьезный вопрос, как формирование резервов по сомнительным долгам, влияющий на показатели бухгалтерской (финансовой) отчетности компаний, регламентирован в нормативно-правовых актах в недостаточном объеме. А это в свою очередь значительно затрудняет проведение финансового анализа коммерческой организации [9].

Основные принципы формирования резерва по сомнительным долгам для целей бухгалтерского учета установлены пунктом 70 Положения по бухгалтерскому учету ${ }^{1}$.

В соответствии с указанным положением, организация вправе создавать резервы по сомнительной дебиторской задолженности, с отнесением сумм резервов на финансовые результаты организации.

«Сомнительной считается дебиторская задолженность организации, которая не погашена или с высокой степенью вероятности не будет погашена в сроки, установленные договором, и не обеспечена соответствующими гарантиями.

Величина резерва определяется отдельно по каждому сомнительному долгу в зависимости от финансового состояния (платежеспособности) должника и оценки вероятности погашения долга полностью или частично.

Если до конца отчетного года, следующего за годом создания резерва сомнительных долгов, этот резерв в какой-либо части не будет использован, то неизрас-

${ }^{1}$ Положение по ведению бухгалтерского учета и бухгалтерской отчетности в Российской Федерации, утвержденное приказом Минфина РФ от 29 июля 1998 г. № 34н.

\section{Baikal Research Journal}

электронный научный журнал Байкальского государственного университета 
ходованные суммы присоединяются при составлении бухгалтерского баланса на конец отчетного года к финансовым результатам» ${ }^{2}$.

Однако, в указанном документе не были предложены методики формирования резерва, лишь дано указание об общих подходах формирования резерва: резерв формируется на основании инвентаризации в отношении каждого сомнительного долга в зависимости от финансового состояния должника и оценки вероятности погашения долга.

Стоит отметить, что для целей налогообложения прибыли предусмотрен конкретный порядок формирования резервов по сомнительным долгам. Так, согласно ст. 266 Налогового Кодекса РФ ${ }^{3}$ (далее - НК РФ):

«Налогоплательщик вправе создавать резервы по сомнительным долгам в порядке, предусмотренном настоящей статьей. Суммы отчислений в эти резервы включаются в состав внереализационных расходов на последнее число отчетного (налогового) периода» ${ }^{4}$

Согласно п. 4 ст. 266 НК РФ: «Сумма резерва по сомнительным долгам определяется по результатам проведенной на последнее число отчетного (налогового) периода инвентаризации дебиторской задолженности и исчисляется следующим образом:

- по сомнительной задолженности со сроком возникновения свыше 90 календарных дней - в сумму создаваемого резерва включается полная сумма выявленной на основании инвентаризации задолженности;

- по сомнительной задолженности со сроком возникновения от 45 до 90 календарных дней (включительно) - в сумму резерва включается 50 процентов от суммы, выявленной на основании инвентаризации задолженности;

- по сомнительной задолженности со сроком возникновения до 45 дней - не увеличивает сумму создаваемого резерва.

При этом сумма создаваемого резерва по сомнительным долгам не может превышать 10 процентов от выручки отчетного (налогового) периода, определяемой в соответствии со ст. 249 НК РФ» ${ }^{5}$.

Предложенная методика не учитывает финансовое состояние должника и зависит только от срока возникновения дебиторской задолженности.

Кроме того, само понятие сомнительного долга, установленное Налоговым Кодексом, значительно отличается от определения, изложенного в Положении для целей бухгалтерского учета.

Таким образом, учитывая нормы пункта 7 Положения по бухгалтерскому учету «Учетная политика организации» ПБУ $1 / 2008^{6}$, в соответствии с которыми, если по конкретному вопросу в нормативно-правовых актах не установлены способы ведения бухгалтерского учета, то при формировании учетной политики осуществляется разработка организацией соответствующего способа, исходя из настоящего и иных положений по бухгалтерскому учету. Также используются Международные стандарты финансовой отчетности, при недостаточной проработке вопроса формирования оценочного резерва по сомнительным долгам. В случае отсутствия закрепленного нормативно-правовыми актами способа формирования оценочного резерва, у экономического субъекта возникает необходимость в разработке такого способа, и он вправе разработать такой способ самостоятельно.

\footnotetext{
${ }^{2}$ Положение по ведению бухгалтерского учета и бухгалтерской отчетности в Российской Федерации, утвержденное приказом Минфина РФ от 29 июля 1998 г. № 34н.

${ }^{3}$ Налоговый Кодекс Российской Федерации (в ред. от 2 июля 2013 г).

${ }^{4}$ Там же.

${ }^{5}$ Там же.

${ }^{6}$ Положение по бухгалтерскому учету: «Учетная политика организации» ПБУ $1 / 2008$, утверж денное Приказом Минфина РФ от 6 октября 2008 г. № 106 н.
}

\section{Baikal Research Journal}


С учетом п. 6 ПБУ $1 / 2008$ «Учетная политика организации», требование осмотрительности предполагает обязанность организаций в случае признания дебиторской задолженности сомнительной сформировать резерв по сомнительным долгам. При этом организация должна избегать создания скрытых резервов.

Резерв по сомнительным долгам является оценочным значением. При определении величины этого резерва важно: с одной стороны, обеспечить резервирование всей выявленной сомнительной задолженности, с целью максимально точного прогнозирования реальной величины безнадежной дебиторской задолженности, с другой стороны - не допустить скрытых резервов, приводящих к необоснованному занижению финансовых результатов компании.

При разработке методики организация должна учитывать условия хозяйствования, отраслевую специфику и анализ статистических данных погашения дебиторской задолженности на протяжении нескольких предшествующих лет. Первостепенная задача для любого экономического субъекта, являющегося кредитором, - классифицировать своих дебиторов, проанализировав основания возникновения задолженности, сроки возникновения и виды контрагентов.

Рассмотрим подходы к классификации дебиторов в целях определения подходов к разработке методики по сомнительным долгам.

По основаниям возникновения дебиторская задолженность может быть классифицирована следующим образом:

- реализация товаров, продукции, выполнение работ, оказание услуг;

- реализация прочего имущества и имущественных прав;

- сдача имущества в аренду (субаренду);

- уплата авансов в связи с приобретением товаров, работ, услуг (авансы выданные);

- выдача беспроцентных займов;

- признание должником или присуждение судом штрафных санкций;

- иные операции, в результате которых у Общества возникло право денежного или иного имущественного требования к контрагенту

По срокам возникновения дебиторская задолженность может быть классифицирована по тем же принципам, что и в Налоговом Кодексе, но временные периоды следует определять с учетом особенностей системы расчетов, фактически сформировавшейся в компании.

По видам контрагентов дебиторская задолженность может быть распределена по группам, учитывающим необходимость обособленного подхода при формировании резерва по сомнительным долгам, например:

- юридические лица;

- физические лица

При формировании резерва по сомнительным долгам следует подразделить всех дебиторов, основываясь на критериях надежности индивидуально взятого контрагента.

При этом могут быть выделены отдельные группы, например:

- контрагенты, в отношении которых возбуждено производство по делу о банкротстве;

- контрагенты, в отношении которых ведется претензионно-исковая работа;

- дочерние и зависимые общества.

Экономический субъект должен установить для себя критерии для оценки надежности контрагентов и выделить отдельные группы риска. Однако, составляя рекомендации для различных контрагентов, следует помнить, что существуют систематические и несистематические виды рисков. И если систематические виды рисков в той или иной степени затрагивают большинство компаний, то с неси-

\section{Baikal Research Journal}


стематическими рисками все намного сложнее, следовательно и подход к оценке каждого контрагента требуется индивидуальный [10].

Именно поэтому при разработке методики, необходимо учитывать трудоемкость обработки информации и учитывать требование рациональности: рациональное ведение бухгалтерского учета, исходя из условий хозяйствования и величины организации. В настоящее время наиболее часто используемыми являются три варианта методик формирования резерва по сомнительным долгам:

1. Методика формирования резерва по сомнительным долгам на основании экспертных оценок [11].

2. Методика формирования резерва по сомнительным долгам, основанная на применении коэффициентов в зависимости от срока возникновения задолженности.

3. Методика формирования резерва по сомнительным долгам, основанная на применении коэффициентов в зависимости от оценки надежности контрагентов.

Рассмотрим перечисленные методики подробнее.

Методика формирования резерва по сомнительным долгам на основании экспертных оценок. При реализации этой методики на предприятии создается группа экспертов, которая на основе анализа финансового состояния должника, сложившихся взаимоотношений между организациями, статистических данных и оценки вероятности погашения долга полностью или частично, экспертным путем определяет необходимость формирования резерва по сомнительным долгам и величину оценочного резерва.

В отношении контрагентов, по которым имеется сомнительная дебиторская задолженность, эксперты проводят оценку их финансового состояния (платежеспособности).

При наличии бухгалтерской (финансовой) отчетности контрагента могут быть рассчитаны следующие показатели, на основании которых делаются выводы о финансовом состоянии контрагента:

- коэффициенты платежеспособности (коэффициент абсолютной ликвидности, коэффициент текущей ликвидности, степень платежеспособности по текущим обязательствам и др.);

- коэффициенты финансовой устойчивости (коэффициент финансовой независимости, коэффициент обеспеченности собственными оборотными средствами и др.).

При отсутствии бухгалтерской (финансовой) отчетности контрагента оценка финансового состояния должника основывается на профессиональном суждении специалистов компании с учетом доступной информации по контрагенту.

Недостатком такого метода могут быть необъективность экспертов к отдельным контрагентам, а также возможность манипулирования величиной оценочного резерва с целью влияния на финансовый результат деятельности компании.

Методика формирования резерва по сомнительным долгам, основанная на применении коэффициентов в зависимости от срока возникновения задолженности. Применение указанной методики расчета величины резерва по сомнительным долгам осуществляется путем группировки задолженности по срокам возникновения задолженности. Конкретная величина процента от суммы дебиторской задолженности, подлежащей отчислению в резерв, соответствует принадлежности рассматриваемого долга к определенной группе. Указанная методика используется в налоговом законодательстве Российской Федерации.

В зависимости от срока просрочки исполнения обязательства в Учетной политике компании устанавливаются коэффициенты резервирования сомнительной задолженности.

\section{Baikal Research Journal}

электронный научный журнал Байкальского государственного университета 
Некоторые компании формируют резерв по сомнительным долгам, как в бухгалтерском, так и в налоговом учете, руководствуясь порядком, установленным НК РФ.

Если мы возьмем в рассмотрение буквальное прочтение нормы пункта 70 ПБУ РФ, основополагающими критериями для внесения задолженности в состав резервируемой являются: финансовое состояние (платежеспособность) должника, оценка вероятности возможного погашения долга полностью или частично.

Учитывая требование п. 6 ПБУ $1 / 2008$ «Учетная политика организации», утвержденного Приказом Минфина РФ от 6 октября 2008 г. № 106н, обуславливающее приоритет экономического содержания фактов и условий хозяйствования перед их правовой формой, применение метода резервирования исключительно в зависимости от периодов просрочки исполнения обязательств, предусмотренного ст. 266 НК РФ, при формировании резерва по сомнительным долгам для целей бухгалтерского учета некорректно.

Тем не менее, метод, основанный на применении коэффициентов в зависимости от срока возникновения задолженности, может быть применен к отдельным группам контрагентов в случаях, когда число контрагентов значительное (например, у компаний, оказывающих коммунальные услуги населению, операторов сотовой связи и т. п.), так как сокращает трудозатраты на обработку данных и расчет величины резерва.

Точность оценочного резерва, сформированного таким способом, будет во многом зависеть от обоснованности установленных сроков и коэффициентов.

Методика формирования резерва по сомнительным долгам, основанная на применении коэффициентов в зависимости от оценки надежности контрагентов. Для формирования резерва вводится система оценки надежности контрагента. Отнесение контрагента к той или иной группе происходит на основании объективных значений, которые имеются в информационной системе компании, и потому может быть автоматизировано.

«Все контрагенты объединяются в четыре группы по уровню надежности:

- надежные контрагенты (группа риска 1);

- обычные контрагенты (группа риска 2);

- ненадежные контрагенты (группа риска 3);

- критические контрагенты (группа риска 4)» [12, с. 3]

«Оценка надежности контрагента производится на основании следующих критериев:

- период просрочки платежа;

- доля в общем объеме продаж (за период);

- доля просроченной необеспеченной задолженности на конец периода» $[12$, с. 4].

Отнесение контрагента к той или иной группе осуществляется на основе интегральной оценки, которая рассчитывается как произведение балльных оценок по всем показателям.

Заключение. Настоящий кризис дает огромное количество возможностей компаниям для развития и пересмотра своих приоритетных направлений. Многие аналитики отмечают, что состояние устойчивого равновесия не привлекает особого интереса, так как «консервирует» экономическую систему и не дает ей возможности к самоизменению и переходу в другое устойчивое состояние [13]. А значит в экономике, как и в жизни, нас интересуют относительно устойчивые, а не абсолютно устойчивые системы [14]. Остается только приспосабливаться под постоянно изменяющуюся экономическую реальность.

«Сейчас нужно забыть про панику, не нужно делать глупостей. Когда рынок падает, то для развития компании не следует рисковать...» - утверждает вла-

\section{Baikal Research Journal}


делец и генеральный директор российского межрегионального холдинга «Капитал-Консалт».

Реалистичная оценка всех активов организации - первый шаг для разработки оптимальной стратегии финансовой стабилизации и дальнейшего экономического развития.

Резерв по сомнительным долгам занимает значимое место в системе бухгалтерского учета любой современной коммерческой организации и требует надлежащей методологической основы его учета. Процесс определения величины резерва многогранен, и большая роль в нем отводится аналитическим исследованиям, проводимым представителями внутренних управленческих структур.

Каждый из предложенных вариантов имеет свои преимущества и недостатки. Однако для адекватной оценки активов конкретного экономического субъекта требуется индивидуальный подход, учитывающий отраслевую специфику, сложившуюся систему расчетов с контрагентами, другие условия финансово-хозяйственной деятельности организации. При формировании учетной политики в отношении методики формирования резерва по сомнительным долгам организацией может быть выбран как один из предложенных вариантов, так и вариант с использованием подходов всех перечисленных методик.

\section{Список использованной литературы}

1. Горчакова М. Е. Развитие банковской системы РФ: динамика и мировой кризис / M. Е. Горчакова // Интеграционные возможности современной экономики : материалы Междунар. науч.-практ. конф. Иркутск, 13-14 сент. 2012 г. / под науч. ред. М. А. Винокурова, И. В. Цвигун. - Иркутск : Изд-во БГУЭП, 2012. - С. 202-207.

2. Базанова Е. ВЭБ: падение экономики в июле временно приостановилось [Электронный ресурс] / Е. Базанова. - Режим доступа: http://www.vedomosti.ru/economics/ articles/2015/08/25/606180-veb-padenie-ekonomiki-vremenno-priostanovilos.

3. Барковский А. Н. Последствия западных санкций и ответных санкций РФ / А. Н. Барковский, С. С. Алабян, О. В. Морозенкова // Российский внешнеэкономический вестник. - 2015. - № 9. - С. 3-7.

4. Сорокина Е. М. Условия составления и содержание ликвидационных балансов / Е. М. Сорокина // Современное состояние и перспективы развития бухгалтерского учета, экономического анализа и аудита : материалы Междунар. науч.-практ. конф. Иркутск, 23 апр. 2016 г. / под науч. ред. Е. М. Сорокиной. - Иркутск : Изд-во БГУЭП, 2016. C. 57-64.

5. Базанова Е. На курсе погорели [Электронный ресурс] / Е. Базанова. - Режим доступа: http://www.vedomosti.ru/economics/articles/2016/01/14/623925-kontse-2015-godachislo-bankrotstv-kompanii-viroslo-oslableniya-rublya.

6. Тутинене Н. Ю. Организация системы внутреннего контроля на предприятии / Н. Ю. Тутинене // Инновации в менеджменте. - 2014. - № 2. - С. 66-70.

7. Тутинене Н. Ю. Финансовый контроллинг в общей системе контроллинга организации / Н. Ю. Тутинене // Контроллинг. - 2010. - № 4. - С. 10-15.

8. Остафий И. Б. Внимание! Безнадежная дебиторская задолженность / И. Б. Остафий // В курсе правового дела. - 2011. - № 16. - С. 71-75.

9. Сажин Ю. Б. Последовательность проведения анализа финансового состояния при контроллинге / Ю. Б. Сажин // Контроллинг услуг : сб. науч. тр. 7-го Междунар. конгресса по контроллингу. Калуга, 13-14 мая 2016 г. / под науч. ред. С. Г. Фалько. - М. : Изд-во НП «Объединение контроллеров», 2016. - С. 205-211

10. Пупенцова С. В. Управление рисками при оценке активов и бизнеса в современных условиях / С. В. Пупенцова // Имущественные отношения в Российской Федерации. 2009. - № 9. - C. 56-64.

11. Демидова И. Н. Методика создания резервов сомнительных долгов / И. Н. Демидова // Контроллинг. - 2012. - № 3. - С. 58-61.

\section{Baikal Research Journal}


12. Кивва Ж Ж. В. Методика формирования резерва по сомнительным долгам в бухгалтерском учете [Электронный ресурс] / Ж⿱ В. В. Кивва // Клуб гл. бухгалтеров. — 2011. — № 6 . C. 71-77. - Режим доступа: http://www.top-personal.ru/kgbmagazineissue.html?247.

13. Чупров С. В. Неустойчивое равновесие и устойчивое неравновесие экономической системы. От воззрений Н. Д. Кондратьева к современной парадигме / С. В. Чупров // Экономическая наука современной России. - 2006. - № 3 (34). - С. 112-120.

14. Виннер Н. Кибернетика, или управление и связь в животном и машине : пер. с англ. / Н. Виннер. - 2-е изд. - М. : Наука, Гл. ред. изд. для зарубеж. стран, 1983. - 344 с.

\section{References}

1. Gorchakova M. E. Development of the RF banking system: dynamics and world crisis. In Vinokurov M. A., Tsvigun I. V. (eds). Integratsionnye vozmozhnosti sovremennoi ekonomiki. Materialy mezhdunarodnoi nauchno-prakticheskoi konferentsii. Irkutsk, 13-14 sentyabrya 2012 g. [Integration Opportunities of Modern Economy. Materials of International Research Conference, Irkutsk, September 13-14, 2012]. Irkutsk, Baikal State University of Economics and Law Publ., 2012, pp. 202-207. (In Russian).

2. Bazanova E. VEB: padenie ekonomiki v iyule vremenno priostanovilos' [VEB: economy shrinking in July is temporarily suspended]. Available at: http://www.vedomosti.ru/economics/ articles/2015/08/25/606180-veb-padenie-ekonomiki-vremenno-priostanovilos. (In Russian).

3. Barkovsky A. N., Alabyan S. S., Morozenkova O. V. Consequences of western sanctions and the RF reciprocal sanctions. Rossiiskii vneshneekonomicheskii vestnik = Russian Foreign Economic Journal, 2015, no. 9, pp. 3-7. (In Russian).

4. Sorokina Ye. M. Conditions of making-out and the content of liquidation balance. In Sorokina Ye. M. (ed.). Sovremennoe sostoyanie i perspektivy razvitiya bukhgalterskogo ucheta, ekonomicheskogo analiza i audita. Materialy Vserossiiskoi nauchno-prakticheskoi konferentsii [Today's State and Prospects of Developing Accounting, Economic Analysis and Auditing. Materials of All-Russian Research Conference]. Irkutsk, Baikal State University of Economics and Law Publ., 2014, pp. 57-64. (In Russian).]. Available at: http://www.vedomosti.ru/economics/articles/2016/01/14/623925-kontse-2015-goda-chislo-bankrotstv-kompanii-viroslo-oslableniya-rublya. (In Russian).

5. Tutinene N. Yu. Organization of the company's internal control system. Innovatsii $v$ menedzhmente = Innovations in Management, 2014, no. 2, pp. 66-70. (In Russian).

6. Tutinene N. Yu. Financial controlling in general system of the company's controlling. Kontrolling $=$ Controlling, 2010, no. 4, pp. 10-15. (In Russian).

7. Ostafii I. B. Beware! Bad accounts receivable. V kurse pravovogo dela = Au Courant of Legal Affairs, 2011, no. 16, pp. 71-75. (In Russian).

8. Sazhin Yu. Sequence of making an analysis of financial conditions in terms of controlling. In Fal'ko S. G. (ed.). Kontrolling uslug. Materialy 7-go Mezhdunarodnogo kongressa po kontrollingu. Kaluga, 13-14 maya 2016 g. [Controlling of services. Materials of 7-th International Controlling Congress. Kaluga, May 13-14, 2016]. Moscow, NP «Obyedinenie kontrollerov» Publ., 2016, pp. 205-211. (In Russian).

9. Pupentsova S. V. Risk management in assessing assets and business in the present context. Imushchestvennye otnosheniya $v$ Rossiiskoi Federatsii = Property Relations in the Russian Federation, 2009, no. 9, pp. 56-64. (In Russian).

10. Demidova I. N. Methods of creating doubtful debts allowances. Kontrolling $=$ Controlling, 2012, no. 3, pp. 58-61. (In Russian).

11. Kivva Zh. V. Methods of creating doubtful debts allowances in accounting. Klub glavnykh bukhgalterov $=$ Club of Chief Accountants, 2011, no. 6, pp. 71-77. Available at: http://www.top-personal.ru/kgbmagazineissue.html?247. (In Russian).

12. Chuprov S. V. Mobile Equilibrium and Stable Equilibrium of the Economic System. From N. D. Kondratyev's Views of the Contemporary Paradigm. Ekonomicheskaya nauka sovremennoi Rossii = Economic Science of Modern Russia, 2006, no. 3 (34), pp. 112-120. (In Russian).

13. Norbert Wiener. Cybernetics or Control and Communication in the Animal and the Machine. Cambridge, Mass., The M.I.T. Press, 1948. (Russ. ed.: Wiener Norbert. Kibernetika, ili upravlenie $i$ svyaz' $v$ zhivotnom $i$ mashine. $2^{\text {nd }}$ ed. Moscow, Nauka Publ., 1983. 344 p.).

\section{Baikal Research Journal}

электронный научный журнал Байкальского государственного университета 


\section{Информация об авторах}

Чашин Леонид Олегович - студент, кафедра экономики и организации производства, Московский государственный технический университет имени Н. Э. Баумана, 105005, Москва, 2-ая Бауманская ул., 5; e-mail: Leo-chashin@yandex.ru.

Клелентьева Светлана Вячеславовна - кандидат экономических наук, доцент, кафедра экономики и организации производства, Московский государственный технический университет имени Н. Э. Баумана, 105005, Москва, 2-ая Бауманская ул., 5; e-mail: klementeva@bmstu.ru.

\section{Authors}

Leonid O. Chashin - Student, Chair of Economics and Business Management, N. E. Bauman Moscow State Technical University, 5 2-nd Bauman St., 105005, Moscow, Russian Federation; e-mail: Leo-chashin@yandex.ru.

Svetlana V. Klementyeva - PhD in Economics, Associate Professor, Chair of Economics and Business Management, N. E. Bauman Moscow State Technical University, 5 2-nd Bauman St., 105005, Moscow, Russian Federation; e-mail: klementeva@bmstu.ru.

\section{Библиографическое описание статьи}

Чашин Л. О. Актуальность формирования резервов по сомнительным долгам / Л. О. Чашин, С. В. Клементьева // Baikal Research Journal. - 2017. — T. 8, № 1. — DOI: 10.17150/2411-6262.2017.8(1).7.

\section{Reference to article}

Chashin L. O., Klementyeva S. V. Relevance of forming allowances for doubtful debts. Baikal Research Journal, 2017, vol. 8, no. 1. DOI: 10.17150/2411-6262.2017.8(1).7. (In Russian).

\section{Baikal Research Journal}

